\title{
Written communication about the use of medications in medical records during patients' hospitalization in Brazil
}

\author{
Lincoln Cavalcante-Santos ${ }^{1}$, Carina Carvalho ${ }^{2}$, Luana Andrade Macêdo ${ }^{3}$, Déborah Mônica \\ Machado Pimentel ${ }^{3}$, Alfredo de Oliveira-Filho ${ }^{4}$, Elizabeth Manias ${ }^{5}$, and Divaldo Lyra \\ Junior $^{2}$ \\ ${ }^{1}$ Universidade de São Paulo Faculdade de Ciências Farmacêuticas de Ribeirão Preto \\ ${ }^{2}$ Universidade Federal de Sergipe \\ ${ }^{3}$ Federal University of Sergipe \\ ${ }^{4}$ Universidade Federal de Alagoas \\ ${ }^{5}$ Deakin University
}

February 5, 2021

\begin{abstract}
Background. Effective communication regarding the use of medications in a hospital environment is a process that contributes to the promotion of patient safety. Despite its importance, especially for medication reconciliation, written communication about the use of medications in medical records remains insufficiently investigated. Aim. To describe the documentation in medical records regarding the medication use process by pharmacists, physicians and nurses on admission, during the hospital stay, and on hospital discharge.Method. A retrospective cross-sectional chart review study was carried out in medical records of patients admitted to a teaching hospital in Northeast Brazil. The study considered all patients admitted between December 2016 and February 2017, aged 18 or older and hospitalized for at least 48 hours. The clinical notes made by pharmacists, physicians and nurses were examined at three transition points of care. Data were collected using a developed questionnaire and aimed at gathering the use of medications prior to hospital admission, changes in the prescribed medications in hospital stay and discharge, as well as prescription non-conformities. Non-conformities were considered as any irregularities reported by the healthcare team involving the medication use process. Communication failures between the three healthcare professionals were also analyzed and classified. Results. This study included 202 patients with a mean age of 51.48 (SD 6.42, range: 19-97) years. There was no record of a patient or relative interview on allergies and adverse drug reactions in $54(26.8 \%)$ physician notes, $44(21.9 \%)$ nursing notes, and $8(22.9 \%)$ of pharmacist notes. Moreover, 1,588 changes in prescriptions were identified during data collection, but only 390 (24.5\%) of these changes were justified. Conclusion. Medication-related information in medical records was incomplete and inconsistent in the clinical notes of the three studied professions, especially in the pharmacists' documentation. Future studies should focus on investigating the consequences of interprofessional communication in patient care.
\end{abstract}

\section{INTRODUCTION}

Effective communication regarding the use of medications in hospital environments is a dynamic and complex process that contributes to the promotion of patient safety. ${ }^{1}$ Regarding communication between the healthcare team, Manias et al. (2016) highlights that when patient information is complete, the continuity of care can be ensured, especially at transition points of care. ${ }^{2}$

In this context, the medical record should be the main document that mirrors the patient's history, from hospital admission to discharge, allowing the continuity of care. ${ }^{3,4}$ Mathioudakis et al. (2016) point out that accurate medical record keeping is integral to good professional practice and the delivery of quality 
healthcare. ${ }^{5}$ According to these authors, medical records must describe treatment details and future treatment recommendations besides every medication administered, prescribed or renewed and any drug allergies.

Recent evidence suggests that when the medical record is not well documented, the transfer of information among healthcare professionals may be impaired. ${ }^{6}$ Communication failure, defined as a flaw in the content, audience, occasion or purpose of the communication act, has been widely reported regarding the use of medications. ${ }^{4,7-10}$ Furthermore, documentation gaps can cause medication errors, such as unintended medication discrepancies. These occur when there is a change in the pharmacotherapy without clinical justification in the transition points of care, or when the intentionality of the change is not recorded. ${ }^{11,12}$ Thus, medication reconciliation emerges as the most effective strategy to solve such issues. ${ }^{13-15}$

The literature points out challenges related to the implementation and consolidation of medication reconciliation, with the quality and reliability of the recording of medication information described as challenges still to be overcome..$^{8,16-18}$ Ideally, all medications that the patient uses before, during and after hospitalization should be documented in the medical record, as well as any changes and justifications for them, improving the communication between the healthcare team. ${ }^{3,19}$ Complete documentation ensures that relevant information for healthcare decision making is available, providing effective evaluation and monitoring of treatment, decreasing episodes of medication omissions and therapeutic duplicity. ${ }^{20,21}$

There are legal issues to ensure good quality documentation recommendations for the United Kingdom, Australia, most of the United States, France and other countries. ${ }^{5}$ In Brazil, studies evaluating the quality and content of medical records are still scarce. Lack of research in this area means that it is difficult to understand how information contained in medical records affects assessment of adverse events and medication errors. ${ }^{22-25}$ Thus, the present study aimed to describe the documentation in medical records regarding the medication use process by pharmacists, physicians and nurses on admission, hospital stay, and hospital discharge.

\section{METHODS}

\section{Design}

We conducted a retrospective cross-sectional, chart review study on the documentation of use of medications in medical records.

\section{Sample/Participants}

The study was carried out in a teaching hospital in Northeast Brazil. The studied wards were: General Medicine, Intensive Care Unit, and Surgical wards. Pharmacists, physicians and nurses worked in all wards, as well as medical residents and other healthcare professionals. We included all patients admitted to the hospital from December 2016 to February 2017 and met the following eligibility criteria: 1) being over 18 years of age and 2) being hospitalized for at least 48 hours in one of the study wards.

\section{Data collection}

Pilot study

In the planning phase of the study, a data collection form was developed using admission, hospitalization and hospital discharge variables extracted from similar studies found in the literature. ${ }^{7,26-28}$ Subsequently, the form was piloted, with a convenience analysis of 92 medical records of patients admitted in the second quarter of 2016, following the same eligibility criteria and in the same study location. Data were analyzed by two independent observers (L.M.C.S. and F.C.J.J.) under the supervision of a third researcher (C.C.S.). Then, the form was expanded to include more information regarding medication use at admission, hospitalization and discharge.

Main measures

The data were collected from April to August 2017. Before data collection, two study coordinators (L.M.C.S. and C.C.S.) trained a team of research assistants (A.S.D., G.A.C.C., L.A.M., R.O.S.S. and T.S.A.) to 
properly apply the data collection form and clarified their questions. The research assistants were pharmacists and researchers, members of the same research group. All medical records were assessed by the team. Cases of divergence regarding the communication failure were resolved by consensus among them.

All data were manually reported in paper medical records which contained all medications prescribed during the hospitalization. The clinical notes made by pharmacists, physicians and nurses, and healthcare professionals involved in the use of medications, were examined at three transition points of care (hospital admission, during the hospital stay, and hospital discharge).

At hospital admission, data were collected from admission forms or, when they were not present, from the first medical note in the patient medical record. Pharmacists and nurses' notes from the first day of hospitalization were also considered as sources of information for hospital admission as well the physician's notes. We considered admission as the first day of hospitalization, and hospital stay from the following days. During the hospital stay, data were extracted from medications prescriptions, pre-anesthetic evaluations, forms requesting other expert opinions and the pharmacists', physicians', and nurses' notes. At hospital discharge, only information presented in the hospital discharge form was evaluated or, when it was not present, the last registered clinical note of a pharmacist, physician, or nurse was considered.

Variables

The data collection step was carried out through a form developed and structured by the research team, that included general patient information (age, sex, ward, nature of hospitalization, hospitalization days, and reason for hospitalization) as well as the following variables. The variables collected from admission clinical notes were: allergies and/or adverse drug reactions; the use of medications prior to hospital admission, including dose, frequency and treatment duration; changes in the use of medications that the patient used before hospital admission, classified according to the type of change (modification or suspension), as well as whether this change was justified; and which time these information were recorded (e.g. admission, hospital stay or hospital discharge).

In turn, the variables from the hospital stay clinical notes were: transfers to other wards in the same institution during hospitalization; changes in the prescribed medications, such as changes of dose, frequency, route of administration, additions, substitutions and suspensions of medications and the justification for such alterations; changes in the prescriptions as a consequence of the intervention of another professional, and whether this suggestion was accepted; referrals to other professionals suggesting interventions in pharmacotherapy; and prescription non-conformities. Non-conformities were considered as any irregularities reported by the healthcare team involving the medication use process. For each professional, considering their specific responsibilities, we assessed different reports in order to classify them as "non-conformities" as below:

- Nurses - non-administration of medications, report of adverse drug events, symptoms that suggests need of pharmacotherapy modification, changes in drug administration time, and route of administration;

- Pharmacists - report of drug interactions, drug-related problems, adverse drug events, symptoms that suggests pharmacotherapy modification, and changes in drug administration time;

- Physicians - absence of written report of justification for pharmacotherapy changes.

Regarding the hospital discharge clinical notes, the following variables were analyzed: changes between the medications used by the patient prior to hospital admission and those prescribed at discharge, classified according to the type of change (modification or suspension), and if there was justification provided for its change; changes in discharge prescriptions as a consequence of the intervention of another professional, and whether this suggestion was accepted; and counter-referral for the patient after hospital discharge.

\section{Data analysis}

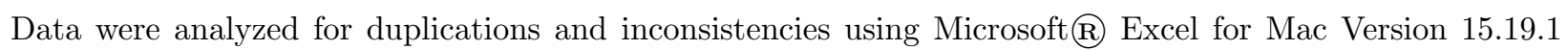
(160212). With the help of this software, the categorical and continuous variables were subjected to descriptive statistical analysis, by calculating frequency counts, percentages, means, standard deviations, minimum 
and maximum values, and confidence intervals.

Analysis of communication failures

The clinical notes of pharmacists, physicians and nurses were also analyzed to identify communication failures about medications. This analysis was performed according to the studies by Manias et al. (2016) and Lingard et al. (2004). ${ }^{2,7}$ Based on this approach, notes regarding the medication use process were transcribed, analyzed and classified.

\section{RESULTS}

In total, 424 patients were admitted to the hospital in the studied wards. Of these, 202 (47.6\%) patients met the inclusion criteria and had, therefore, their medical records analyzed. A total of 222 patients were excluded from the final sample for the following reasons: patient discharged in less than 48 hours ( $\mathrm{n}=208$, $49.0 \%)$, medical records not found $(n=8,1.9 \%)$ or patients aged under 18 years old $(n=6 ; 1.4 \%)$.

Of the 202 records analyzed, $121(59.9 \%)$ were from female patients and had a mean age of 51.48 (SD 16.42 , range: 19 to 97$)$ years. Table 1 shows the complete patients' characteristics. The most prevalent reason for hospitalization was cholelithiasis surgery or obstruction of the biliary tract (with or without cholecystitis) $(\mathrm{n}=20,9.9 \%)$, followed by breast cancer $(\mathrm{n}=9,4.4 \%)$, benign thyroid neoplasm $(\mathrm{n}=8,3.9 \%)$ and chronic obstructive pulmonary disease $(\mathrm{n}=8,3.9 \%)$.

\section{[INSERT TABLE 1]}

Documentation of pharmacists', physicians' and nurses' clinical notes in medical records

\section{Hospital admission}

At hospital admission, the pharmacist was the professional who least recorded the medications used prior to admission, with a mean of 2.6 SD 4.5 (0 to 22) days of delay to report such information in the medical record. Table 2 shows the report of medication-related information present in the clinical notes of pharmacists, physicians and nurses.

Regarding the record of medications used by the patient prior to admission, 86 changes were identified. These changes were classified as: suspension of these medications $(n=64,74.4 \%)$; and alteration of dose, frequency or route of administration $(n=22,25.6 \%)$. Furthermore, the timing of documentation was different among the healthcare professionals. While physicians and nurses reported information on allergies and adverse drug reactions predominantly on admission, pharmacists reported this information in $44.4 \%$ ( $\mathrm{n}=12$ ) of their admission clinical notes. Pharmacist records on the patients' previous pharmacotherapy were also identified mainly during the hospital stay $(\mathrm{n}=18,64.3 \%)$.

\section{[INSERT TABLE 2]}

\section{Hospital stay}

Regarding the prescribed medications during hospitalization, 1,588 changes were identified, with an average of 9.45 (I.C. $95 \%$; 7.71 to 11.19) changes per patient. Only 390 (24.5\%) of such changes were justified. Of the justified changes, most were the addition of medications $(n=199,51.0 \%)$, followed by treatment suspension $(n=84,21.5 \%)$ and adjustments in dose $(n=50,12.8 \%)$. Furthermore, 29 justified changes related to recommendations made by physicians, two related to nurses, and one related to pharmacists. The recommendations of these professionals were accepted in all 32 cases.

In $48(23.7 \%)$ of the 202 medical records, there were 116 non-conformities related to medications in the nurses' clinical notes. In addition, 59 direct references to other professionals were observed. The physicians were the most mentioned $(n=39,66.1 \%)$, followed by nurses $(n=19,32.2 \%)$ and nutritionists $(n=1,1.7 \%)$. From the references described, 26 (44.0\%) indicated interventions in the patients' pharmacotherapy. Among the actions suggested, the suspension of medication administration, given the patients' clinical condition and changes in administration time by physician orders, were observed. 
Only 11 (5.4\%) medical records contained a pharmacist report of non-conformities related to the use of medications. Seventeen non-conformities were identified, of which four $(25.0 \%)$ related to the risk of drug interactions, three (18.7\%) to the identification of medication discrepancies and two (12.5\%) to allergic reactions after medication administration. In addition, the pharmacist documented the conduct performed to solve eight $(50 \%)$ of these non-conformities. Reference to the physician was found in three cases.

\section{Hospital discharge}

Hospital discharge reports showed that, of the 202 patients, 93 (46.0\%) had a medication prescribed for discharge. Of these 93 prescriptions, $22(23.7 \%)$ were new medications and $71(76.3 \%)$ of the prescriptions presented changes between the medications used prior to hospital admission and those prescribed at discharge. Of these changes, only $35.1 \%(n=77)$ had a justification, similar to the justified changes found in hospital stay, in which addition of medications were the most prevalent (73\%), followed by treatment suspension $(12 \%)$ and adjustments in dose $(9 \%)$.

The present study also verified that, in 13 (18.3\%) discharge prescriptions, changes between the patient's previous medication and medications that the patient would use after hospitalization were made by the intervention of other medical specialties. Of these changes, only nine made direct reference to the physicians who suggested them, and they were accepted in all cases.

When assessing the nurses' discharge notes, we found only one $(0.4 \%)$ discharge medication was documented. The report was related to a continued treatment with an antiretroviral drug. No records were found on the medication use after discharge in the pharmacists' clinical notes. In addition, record of counter-referrals at hospital discharge was observed in $161(79.7 \%)$ physicians' clinical notes, followed by one $(0.4 \%)$ nurse's clinical note, and no pharmacists' documentation was found.

Communication failures in medical records

Table 3 defines the types of communication failures and shows examples extracted from medical records.

[INSERT TABLE 3]

\section{DISCUSSION}

To the best of our knowledge, this is the first study to describe written communication about medication use during admission, hospital stay and discharge in Brazil. Our findings show some gaps in documentation that may have compromised the understanding of medication use processes within the hospital environment.

The physicians' and nurses' clinical notes were present in almost all medical records analyzed, while the pharmacists' documentation was less prevalent. Other studies have shown that pharmacists are less likely to document their interventions. ${ }^{29-33}$ Deficiencies in training, lack of involvement in the healthcare team, as well as clarity of work processes are factors that may influence this finding. Furthermore, Rixon et al. (2014) states that the healthcare team prefers spoken communication over pharmacists' written communication when searching for immediate medication information. ${ }^{31}$ In light of this view, it becomes unclear what are the pharmacists' roles in a multiprofessional patient care environment, since the gaps of documentation do not allow a proper analysis of their interventions. This omission may impair patient care, considering that the integration of pharmacists into core healthcare teams seemed to facilitate better health outcomes, better team decision making regarding medication use, improved continuity of care and patient safety. ${ }^{2,29,40-43,31,32,34-39}$

Most nurses' and pharmacists' notes did not present information on the medication use at admission and hospital discharge, especially the absence of treatment duration. Omission of relevant information on the use of medications may increase days of hospitalization, lead to treatment interruptions and compromise patient safety. ${ }^{44-48}$ Studies show that omissions occur frequently when health professionals do not question about medication use or when they fail to record the patient's answer on this matter. ${ }^{48,49,58-61,50-57}$ Moreover, it is important that health professionals have clarity of their roles and know what information regarding their expertise must be reported in medical records. This clarity enables continuity of care, considering that, in the medication use process, one professional could depend on others' evaluation. If the healthcare team wants to 
work collaboratively, complete documentation is essential to enable a more reliable decision-making process regarding patient care.

A notorious number of changes in medication use before and during hospitalization was observed, as well as other studies in literature. ${ }^{3,62-65}$ However, only a few changes had written justifications. The absence of such information compromises the intentionality analysis of the discrepancies, which impairs medication reconciliation and patient safety. The New South Wales Therapeutic Advisory Group has used documented justifications as a quality indicator for medication use in Australian hospitals, which highlights their importance in driving improvements within the contemporary practice. ${ }^{66}$

Most medical records presented some type of deficiency in written communication among the professionals evaluated. Vermeir et al. (2015) emphasize that, although spoken communication among healthcare professionals is essential, in clinical practice, written communication remains the most common means of interaction among them. ${ }^{67}$ Manias et al. (2016) associated communication fails with institution challenges and interprofessional relationships. ${ }^{2}$ Future studies should be directed to the analysis of the dimensions of communication and how these might interact to promote an efficient transfer of information regarding medications use in hospital settings.

Given the challenges related to documentation, electronic medical records and information software packages have been shown as strategic tools to assist written communication. Their use has been reported to improve interprofessional communication, decrease medication errors and length of intensive care unit stay. ${ }^{68-73}$ In Brazil, most medical records are paper based as it was in the studied hospital. ${ }^{74,75}$ The use of paper charts is associated with problems such as prescription illegibility and incompleteness of patient information. ${ }^{76}$ Some studies indicate that the quality of documentation does not necessarily depend on the adoption of electronic medical records, as it depends on the quality of the process, and, thus, healthcare professional training is required to make good documentation, with the electronic medical records as tools in this process. ${ }^{77-81}$ Although electronic medical records are recognized as an important strategy for time optimization, their adoption should aim at the integration and qualification of documentation processes, maximizing interaction with the most accurate source of the information - the patient. ${ }^{82,83}$

The present study has strengths and limitations. We conducted an analysis of documentation of the three professional groups (nurses, physicians, pharmacists) who were directly involved in medication use processes. In addition, the investigation of the completeness of medication-related information in transition points of care is another important factor that deserves to be emphasized.

This study also has some limitations since we did not investigate the clinical relevance of the completeness of information in hospitalization, which could be useful to assess the risks of absent information for patient safety. Another limitation was the lack of proportional analysis of the number of healthcare professionals in the study setting, which could enrich the interpretation of findings.

\section{CONCLUSION}

Our findings revealed that medication-related information in medical records was incomplete and inconsistent in the clinical notes of the three studied professions, especially in the pharmacists' documentation. These written communication failures may compromise patient safety, considering that medical records should legally describe healthcare professionals' work processes. Once this study found several gaps, we highlight an alert for failures in these professionals' practices. Future studies should add depth to these discussions, investigating the consequences of interprofessional communication in patient care.

\section{AUTHORSHIP}

LMCS, CCS and LAM were major contributors in writing the manuscript, responsible for study concept and design, acquisition, analysis and interpretation of data, and drafting of the manuscript. DMMP, ADOF and DPLJ also contributed to the study concept and design, drafting of the manuscript, and critical revision of the manuscript for important intellectual content. LMCS, CCS and LAM performed the analysis and interpretation of data. EM substantively revised the manuscript for important intellectual content. All authors 
have read and approved the submitted version of the manuscript. All authors have also agreed both to be personally accountable for their own contributions, and to ensure that questions related to the accuracy or integrity of any part of the work were appropriately investigated and resolved.

\section{Ethics and other permissions}

The study was authorized by the Hospital's Board of Directors and approved by the Research Ethics Committee of the Federal University of Sergipe under the number 08125912.5.0000.0058. The collected data were for exclusive use of the researchers having secured the confidentiality of information obtained in accordance with the resolution CNS no ${ }^{0}$ 466/2012.

\section{Conflict of interests}

No known conflict of interests.

\section{Data availability statement}

The datasets used and/or analysed in the current study are available from the corresponding author on reasonable request.

\section{References}

1. Manias E. Medication communication: a concept analysis. J Adv Nurs . 2010;66(4):933-943. doi:10.1111/j.1365-2648.2009.05225.x

2. Manias E, Gerdtz M, Williams A, McGuiness J, Dooley M. Communicating about the management of medications as patients move across transition points of care: an observation and interview study. $J$ Eval Clin Pract . 2016;22(5):635-643. doi:10.1111/jep.12507

3. Zierler-Brown S, Brown TR, Chen D, Blackburn RW. Clinical documentation for patient care: Models, concepts, and liability considerations for pharmacists. Am J Heal Pharm . 2007;64(17):1851-1858. doi:10.2146/ajhp060682

4. Scotten M, Manos EL, Malicoat A, Paolo AM. Minding the gap: Interprofessional communication during inpatient and post discharge chasm care. Patient Educ Couns . 2015;98(7):895-900. doi:10.1016/j.pec.2015.03.009

5. Mathioudakis A, Rousalova I, Gagnat AA, Saad N, Hardavella G. How to keep good clinical records. Breathe . 2016;12(4):369-373. doi:10.1183/20734735.018016

6. Hias J, Van der Linden L, Spriet I, et al. Predictors for unintentional medication reconciliation discrepancies in preadmission medication: a systematic review. Eur J Clin Pharmacol . 2017;73(11):1355-1377. doi:10.1007/s00228-017-2308-1

7. Lingard L, Espin S, Whyte S, et al. Communication failures in the operating room: an observational classification of recurrent types and effects. Qual Saf Heal Care . 2004;13(5):330-334. doi:10.1136/qshc.2003.008425

8. Frei P, Huber LC, Simon RW, Bonani M, Lüscher TF. Insufficient Medication Documentation at Hospital Admission of Cardiac Patients: A Challenge for Medication Reconciliation. J Cardiovasc Pharmacol . 2009;54(6):497-501. doi:10.1097/fjc.0b013e3181be75b4

9. Starmer AJ, Spector ND, Srivastava R, et al. Changes in Medical Errors after Implementation of a Handoff Program. N Engl J Med . 2014;371(19):1803-1812. doi:10.1056/nejmsa1405556

10. Uitvlugt EB, Siegert CEH, Janssen MJA, Nijpels G, Karapinar-Çarkit F. Completeness of medicationrelated information in discharge letters and post-discharge general practitioner overviews. Int J Clin Pharm . 2015;37(6):1206-1212. doi:10.1007/s11096-015-0187-z

11. The Joint Commission. Sentinel event data: Root causes by event type. Published 2014. Accessed August 18, 2017. http://www.jointcommission.org/sentinel_event_statistics 
12. Almanasreh E, Moles R, Chen TF. The medication reconciliation process and classification of discrepancies: a systematic review.Br J Clin Pharmacol . 2016;82(3):645-658. doi:10.1111/bcp.13017

13. World Health Organization. Assuring Medication Accuracy at Transitions in Care. Patient Safety Solutions 1 . https://www.who.int/patientsafety/solutions/patientsafety/PS-Solution6.pdf?ua=1. Published 2007.

14. Institute for Safe Medication Practices Canada. Medication Reconciliation (MedRec). Published 2017. Accessed September 9, 2017. https://www.ismp-canada.org/medrec/

15. Institute for Healthcare Improvement. Medication Reconciliation to Prevent Adverse Drug Events. Published 2017. Accessed September 9, 2017. http://www.ihi.org/Topics/ADEsMedicationReconciliation/Pages/default.aspx

16. Pevnick JM, Shane R, Schnipper JL. The problem with medication reconciliation. BMJ Qual Saf . 2016;25(9):726-730. doi:10.1136/bmjqs-2015-004734

17. Donaldson LJ, Kelley ET, Dhingra-Kumar N, Kieny M-P, Sheikh A. Medication Without Harm: WHO's Third Global Patient Safety Challenge.Lancet . 2017;389(10080):1680-1681. doi:10.1016/s01406736(17)31047-4

18. Rose AJ, Fischer SH, Paasche-Orlow MK. Beyond Medication Reconciliation. JAMA . 2017;317(20):2057. doi:10.1001/jama.2017.4628

19. Wu R. Turning the page on hospital communications slowly. BMJ Qual Saf . 2016;26(1):4-6. doi:10.1136/bmjqs-2015-005031

20. Jensen TB. Design principles for achieving integrated healthcare information systems. Health Informatics J . 2013;19(1):29-45. doi:10.1177/1460458212448890

21. Ellingsen G, Monteiro E. The organizing vision of integrated health information systems. Health Informatics J . 2008;14(3):223-236. doi:10.1177/1081180x08093333

22. Mendes W, Martins M, Rozenfeld S, Travassos C. The assessment of adverse events in hospitals in Brazil. Int J Qual Heal Care . 2009;21(4):279-284. doi:10.1093/intqhc/mzp022

23. Martins M, Travassos C, Mendes W, Pavão ALB. Hospital deaths and adverse events in Brazil. BMC Health Serv Res . 2011;11:223. doi:10.1186/1472-6963-11-223

24. Pavão ALB, Andrade D, Mendes W, Martins M, Travassos C. Estudo de incidência de eventos adversos hospitalares, Rio de Janeiro, Brasil: avaliação da qualidade do prontuário do paciente. Rev Bras Epidemiol . 2011;14(4):651-661. doi:10.1590/s1415-790x2011000400012

25. Paixão Nunes CF, Andreoli PBA, Ferracini FT, Barros CG. A Survey of Medication Error Prevalence in a Brazilian Health Center. J Nurs Care Qual . 2013;28(1):92-97. doi:10.1097/ncq.0b013e3182641b1b

26. Jylha V, Saranto K, Bates DW. Preventable adverse drug events and their causes and contributing factors: the analysis of register data.Int J Qual Heal Care . 2011;23(2):187-197. doi:10.1093/intqhc/mzq085

27. Portela MC, Pronovost PJ, Woodcock T, Carter P, Dixon-Woods M. How to study improvement interventions: a brief overview of possible study types: Table 1. BMJ Qual Saf . 2015;24(5):325-336. doi:10.1136/bmjqs-2014-003620

28. Ngo E, Patel N, Chandrasekaran K, Tajik AJ, Paterick TE. The Importance of the Medical Record: A Critical Professional Responsibility. J Med Pract Manage . 2016;31(5):305-308.

29. Makowsky MJ, Schindel TJ, Rosenthal M, Campbell K, Tsuyuki RT, Madill HM. Collaboration between pharmacists, physicians and nurse practitioners: A qualitative investigation of working relationships in the inpatient medical setting. J Interprof Care . 2009;23(2):169-184. doi:10.1080/13561820802602552 
30. Pullinger W, Franklin BD. Pharmacists' documentation in patients' hospital health records: issues and educational implications. Int J Pharm Pract . 2010;18(2):108-115. doi:10.1211/ijpp.18.02.0006

31. Rixon S, Braaf S, Williams A, Liew D, Manias E. Pharmacists' Interprofessional Communication About Medications in Specialty Hospital Settings. Health Commun . 2014;30(11):1065-1075. doi:10.1080/10410236.2014.919697

32. Wang Y-Y, Wan Q-Q, Lin F, Zhou W-J, Shang S-M. Interventions to improve communication between nurses and physicians in the intensive care unit: An integrative literature review. Int J Nurs Sci . 2018;5(1):8188. doi:10.1016/j.ijnss.2017.09.007

33. Hammer A, Wagner A, Rieger MA, Manser T. Assessing the quality of medication documentation: development and feasibility of the MediDocQ instrument for retrospective chart review in the hospital setting.BMJ Open . 2019;9(11):e034609. doi:10.1136/bmjopen-2019-034609

34. van der Kam W, Meyboom de Jong B, Tromp T, Moorman P, van der Lei J. Effects of electronic communication between the GP and the pharmacist. The quality of medication data on admission and after discharge.Fam Pract . 2001;18(6):605-609. doi:10.1093/fampra/18.6.605

35. Kaleemuddin M, Sankham RD, Bhojraj S. The Role of the Clinical Pharmacist in Poison-Related Admissions in a Secondary Care Hospital.Aust J Hosp Pharm . 2001;31(1):26-30. doi:10.1002/jppr200131126

36. Abuyassin BH, Aljadhey H, Al-Sultan M, Al-Rashed S, Adam M, Bates DW. Accuracy of the medication history at admission to hospital in Saudi Arabia. Saudi Pharm J . 2011;19(4):263-267. doi:10.1016/j.jsps.2011.04.006

37. Al-Aqee S, Al-Anizi R, Al-Fadel N, Alkortas D. Clinical Pharmacist Interventions and Barriers for Documenting these Interventions at King Faisal Specialist Hospital and Research Center. J King Abdulaziz Univ . 2012;19(1):89-101. doi:10.4197/med.19-1s.6

38. Galvin M, Jago-Byrne M-C, Fitzsimons M, Grimes T. Clinical pharmacist's contribution to medication reconciliation on admission to hospital in Ireland. Int J Clin Pharm . 2012;35(1):14-21. doi:10.1007/s11096012-9696-1

39. Sevel TK. CP-137 Ensuring safe medical treatment during planned hospital admission by clinical pharmacist telephone contact. Eur J Hosp Pharm . 2014;21(Suppl 1):A55.2-A55. doi:10.1136/ejhpharm-2013000436.135

40. Faerch K, Bulow C, Dinsen-Andersen C. Factors influencing physician's use of pharmacist notes. Int $J$ Clin Pharm . 2016;38:536.

41. Wei L, Yang X, Li J, et al. Effect of pharmaceutical care on medication adherence and hospital admission in patients with chronic obstructive pulmonary disease (COPD): a randomized controlled study. $J$ Thorac Dis . 2014;6(6):656-662. doi:10.3978/j.issn.2072-1439.2014.06.20

42. Tong EY, Roman C, Mitra B, et al. Partnered pharmacist charting on admission in the General Medical and Emergency Short-stay Unit - a cluster-randomised controlled trial in patients with complex medication regimens. J Clin Pharm Ther . 2016;41(4):414-418. doi:10.1111/jcpt.12405

43. Marotti SB, Cheh RMT, Ponniah A, Phuong H. The utility of a medical admissions pharmacist in a hospital in Australia. Int J Clin Pharm . 2017;39(2):403-407. doi:10.1007/s11096-017-0438-2

44. Lau HS, Florax C, Porsius AJ, De Boer A. The completeness of medication histories in hospital medical records of patients admitted to general internal medicine wards. Br J Clin Pharmacol . 2001;49(6):597-603. doi:10.1046/j.1365-2125.2000.00204.x

45. Nester TM, Hale LS. Effectiveness of a pharmacist-acquired medication history in promoting patient safety. Am J Heal Pharm . 2002;59(22):2221-2225. doi:10.1093/ajhp/59.22.2221 
46. Spinewine A, Claeys C, Foulon V, Chevalier P. Approaches for improving continuity of care in medication management: a systematic review. Int J Qual Heal Care . 2013;25(4):403-417. doi:10.1093/intqhc/mzt032

47. Mills PR, Weidmann AE, Stewart D. Hospital electronic prescribing system implementation impact on discharge information communication and prescribing errors: a before and after study. Eur J Clin Pharmacol . 2017;73(10):1279-1286. doi:10.1007/s00228-017-2274-7

48. Silvestre CC, Santos LMC, de Oliveira-Filho AD, de Lyra DP. 'What is not written does not exist': the importance of proper documentation of medication use history. Int J Clin Pharm . 2017;39(5):985-988. doi:10.1007/s11096-017-0519-2

49. Kimland E, Bottiger Y, Lindemalm S. Recent drug history in children visiting a pediatric emergency room and documentation in medical records. Eur J Clin Pharmacol . 2011;67(10):1085-1089. doi:10.1007/s00228011-1057-9

50. Bacon T, Fan K, Desai M. Electronic medical record and glaucoma medications: connecting the medication reconciliation with adherence. Clin Ophthalmol . 2016;10:221-225. doi:10.2147/opth.s92785

51. Gleason KM, Groszek JM, Sullivan C, Rooney D, Barnard C, Noskin GA. Reconciliation of discrepancies in medication histories and admission orders of newly hospitalized patients. Am J Heal Pharm . 2004;61(16):1689-1695. doi:10.1093/ajhp/61.16.1689

52. Cornish PL, Knowles SR, Marchesano R, et al. Unintended Medication Discrepancies at the Time of Hospital Admission. Arch Intern Med . 2005;165(4):424. doi:10.1001/archinte.165.4.424

53. Carter MK, Allin DM, Scott LA, Grauer D. Pharmacist-acquired medication histories in a university hospital emergency department.Am J Heal Pharm . 2006;63(24):2500-2503. doi:10.2146/ajhp060028

54. Cornu P, Steurbaut S, Leysen T, et al. Effect of Medication Reconciliation at Hospital Admission on Medication Discrepancies During Hospitalization and at Discharge for Geriatric Patients. Ann Pharmacother . 2012;46(4):484-494. doi:10.1345/aph.1q594

55. Allende-Bandres MA, Arenere-Mendoza M, Gutierrez-Nicolas F, Calleja-Hernandez MA, Ruiz La Iglesia F. Pharmacist-led medication reconciliation to reduce discrepancies in transitions of care in Spain.Int J Clin Pharm . 2013;35(6):1083-1090. doi:10.1007/s11096-013-9824-6

56. Bjeldbak-Olesen M, Danielsen AG, Tomsen DV, Jakobsen TJ. Medication reconciliation is a prerequisite for obtaining a valid medication review. Dan Med $J$. 2013;60(4):A4605.

57. Kripalani S, LeFevre F, Phillips CO, Williams M V, Basaviah P, Baker DW. Deficits in Communication and Information Transfer Between Hospital-Based and Primary Care Physicians. JAMA . 2007;297(8):831. doi:10.1001/jama.297.8.831

58. Witherington EMA, Pirzada OM, Avery AJ. Communication gaps and readmissions to hospital for patients aged 75 years and older: observational study. Qual Saf Heal Care . 2008;17(1):71-75. doi:10.1136/qshc.2006.020842

59. Courtenay M, Griffiths M. Medication Safety: An Essential Guide . Cambridge University Press ; 2009.

60. Gandara E, Moniz T, Ungar J, et al. Communication and information deficits in patients discharged to rehabilitation facilities: An evaluation of five acute care hospitals. J Hosp Med . 2009;4(8):E28-E33. doi:10.1002/jhm.474

61. Ooi CE, Rofe O, Vienet M, Elliott RA. Improving communication of medication changes using a pharmacist-prepared discharge medication management summary. Int J Clin Pharm . 2017;39(2):394-402. doi:10.1007/s11096-017-0435-5

62. Himmel W, Kochen MM, Sorns U, Hummers-Pradier E. Drug changes at the interface between primary and secondary care. Int J Clin Pharmacol Ther . 2004;42(02):103-109. doi:10.5414/cpp42103 
63. Grimmsmann T, Schwabe U, Himmel W. The influence of hospitalisation on drug prescription in primary care - a large-scale follow-up study.Eur J Clin Pharmacol . 2007;63(8):783-790. doi:10.1007/s00228-007$0325-1$

64. Viktil KK, Blix HS, Eek AK, Davies MN, Moger TA, Reikvam A. How are drug regimen changes during hospitalisation handled after discharge: a cohort study. BMJ Open . 2012;2(6):e001461. doi:10.1136/bmjopen-2012-001461

65. Harris CM, Sridharan A, Landis R, Howell E, Wright S. What Happens to the Medication Regimens of Older Adults During and After an Acute Hospitalization? J Patient Saf . 2013;9(3):150-153. doi:10.1097/pts.0b013e318286f87d

66. NSW Therapeutic Advisory Group. National Quality Use of Medicines Indicators for Australian Hospitals. Published 2014. Accessed September 19, 2017. http://www.nswtag.org.au/wpcontent/uploads/2017/08/manual.pdf

67. Vermeir P, Vandijck D, Degroote S, et al. Communication in healthcare: a narrative review of the literature and practical recommendations. Int J Clin Pract . 2015;69(11):1257-1267. doi:10.1111/ijcp.12686

68. Edwards K-E, Hagen SM, Hannam J, Kruger C, Yu R, Merry AF. A randomized comparison between records made with an anesthesia information management system and by hand, and evaluation of the Hawthorne effect. Can J Anesth Can d'anesthesie . 2013;60(10):990-997. doi:10.1007/s12630-013-0003-y

69. Grigg E, Palmer A, Grigg J, et al. Randomised trial comparing the recording ability of a novel, electronic emergency documentation system with the AHA paper cardiac arrest record. Emerg Med $J$. 2013;31(10):833-839. doi:10.1136/emermed-2013-202512

70. Alex S, Adenew AB, Arundel C, Maron DD, Kerns JC. Medication Errors Despite Using Electronic Health Records. Qual Manag Health Care . 2016;25(1):32-37. doi:10.1097/qmh.0000000000000080

71. Anderson RJ, Sparbel K, Barr RN, Doerschug K, Corbridge S. Electronic Health Record Tool to Promote Team Communication and Early Patient Mobility in the Intensive Care Unit. Crit Care Nurse . 2018;38(6):23-34. doi:10.4037/ccn2018813

72. Manca DP. Do electronic medical records improve quality of care? Yes. Can Fam Physician . 2015;61(10):846-847,850-851.

73. Bardach SH, Real K, Bardach DR. Perspectives of healthcare practitioners: An exploration of interprofessional communication using electronic medical records. J Interprof Care . 2017;31(3):300-306. doi:10.1080/13561820.2016.1269312

74. Cruz HL da, Mota FK da C, Araujo LU, Bodevan EC, Seixas SRS, Santos DF. The utility of the records medical: factors associated with the medication errors in chronic disease. Rev Lat Am Enfermagem . 2017;25:e2967. doi:10.1590/1518-8345.2406.2967

75. Silva FG, Tavares-Neto J. Avaliacao dos prontuarios medicos de hospitais de ensino do Brasil. Rev Bras Educ Med . 2007;31(2):113-126. doi:10.1590/s0100-55022007000200002

76. Volpe CRG, Melo EMM de, Aguiar LB de, Pinho DLM, Stival MM. Risk factors for medication errors in the electronic and manual prescription.Rev Lat Am Enfermagem . 2016;24:e2742. doi:10.1590/15188345.0642 .2742

77. Lehnbom EC, Raban MZ, Walter SR, Richardson K, Westbrook JI. Do Electronic Discharge Summaries Contain More Complete Medication Information? A Retrospective Analysis of Paper versus Electronic Discharge Summaries. Heal Inf Manag J . 2014;43(3):4-12. doi:10.1177/183335831404300301

78. Callen JL, McIntosh J, Li J. Accuracy of medication documentation in hospital discharge summaries: A retrospective analysis of medication transcription errors in manual and electronic discharge summaries. Int $J$ Med Inform . 2010;79(1):58-64. doi:10.1016/j.ijmedinf.2009.09.002 
79. Callen JL, Alderton M, McIntosh J. Evaluation of electronic discharge summaries: A comparison of documentation in electronic and handwritten discharge summaries. Int J Med Inform . 2008;77(9):613-620. doi:10.1016/j.ijmedinf.2007.12.002

80. Wrightson WAG. A Comparison of Electronic and Handwritten Anaesthetic Records for Completeness of Information. Anaesth Intensive Care . 2010;38(6):1052-1058. doi:10.1177/0310057x1003800615

81. Marshall K, Urban R, Armitage G, Morgan J, Blenkinsopp A. Communicating about medication. Who, what, where, when, how? In:Host Publication. John Wiley \& Sons Ltd; 2013:20-21.

82. Kummerow Broman K, Kensinger C, Hart H, Mathisen J, Kripalani S. Closing the loop: a process evaluation of inpatient care team communication. BMJ Qual Saf . 2015;26(1):30-32. doi:10.1136/bmjqs2015-004580

83. Coralic Z. Medication reconciliation studies: High quantity, low quality. Am J Heal Pharm . 2019;76(24):1996-1997. doi:10.1093/ajhp/zxz238

Table 1. Characteristics of patients admitted to General, Intensive Care Unit, and Surgical wards of a teaching hospital in Northeast Brazil. [n=202]

\begin{tabular}{ll}
\hline Variables analyzed & $\mathbf{N}(\mathbf{\%})$ \\
Gender & \\
Feminine & $121(59.9 \%)$ \\
Masculine & $81(40.1 \%)$ \\
Age & \\
$18-29$ years & $21(10.4 \%)$ \\
$30-39$ years & $30(14.9 \%)$ \\
$40-49$ years & $41(20.3 \%)$ \\
$50-59$ years & $47(23.3 \%)$ \\
$60-69$ years & $38(18.8 \%)$ \\
More than 70 years & $25(12.3 \%)$ \\
Nature of hospitalization & \\
Admitted from home & $192(95.0 \%)$ \\
Admitted from another hospital & $10(5.0 \%)$ \\
Ward & \\
Surgical & $124(61.4 \%)$ \\
General & $77(38.1 \%)$ \\
Intensive Care Unit & $1(0.5 \%)$ \\
Hospitalization days & \\
$1-4$ days & $103(51.0 \%)$ \\
$5-9$ days & $40(19.8 \%)$ \\
10 - 14 days & $25(12.4 \%)$ \\
15 - 19 days & $9(4.4 \%)$ \\
20 - 24 days & $11(5.4 \%)$ \\
$25-29$ days & $7(3.5 \%)$ \\
More than 30 days & $7(3.5 \%)$ \\
Transfers to other wards & \\
Intrahospital & $15(7.4 \%)$ \\
Interhospital & $1(0.5 \%)$ \\
\hline
\end{tabular}

$\mathrm{N}=$ number of patients 
Table 2.

Medication-related information present in the clinical notes of pharmacists, physicians and nurses of a teaching hospital in Northeast Brazil.

Variables analyzed

Total number of records

\section{HOSPITAL}

ADMISSION

Written record of

allergies and/or adverse

drug reactions

Written record of the use

of medications prior to

admission

Patient denies the use of

medications prior to

admission

Dose

Frequency

Treatment duration

HOSPITAL STAY

Non-conformities

related to medication

use process

Referrals to other

professionals suggesting

interventions in

pharmacotherapy

HOSPITAL

\section{DISCHARGE}

Report of medications use after hospitalization

Counter-referrals
Table 2 .

Medication-related information present in the clinical notes of pharmacists, physicians and nurses of a teaching hospital in Northeast Brazil.

Nurses' clinical notes

n $(\%)$

$201(99.5 \%)$

$157(77.7 \%)$

$56(27.7 \%)$

$12(5.9 \%)$

$8(4.0 \%)$

$6(3.0 \%)$

$1(0.5 \%)$

$48(23.7 \%)$

$28(13.8 \%)$
Table 2.

Medication-related information present in the clinical notes of pharmacists, physicians and nurses of a teaching hospital in Northeast Brazil.

Pharmacists' clinical notes

n $(\%)$

$35(17.3 \%)$

$27(13.4 \%)$

$28(13.9 \%)$

$5(2.5 \%)$

$16(7.9 \%)$

$15(7.4 \%)$

$1(0.5 \%)$

$11(5.4 \%)$

$10(4.9 \%)$
Table 2.

Medication-related information present in the clinical notes of pharmacists, physicians and nurses of a teaching hospital in Northeast Brazil.

Physicians' clinical notes

n $(\%)$

$202(100 \%)$

$148(73.3 \%)$

$167(82.7 \%)$

$37(18.3 \%)$

$102(50.5 \%)$

$90(44.5 \%)$

$13(6.4 \%)$

$97(48.0 \%)$

$32(15.8 \%)$

Abbreviation: NA, not applicable.

Table 3. Definition of types of communication failures with examples obtained from the medical records of General, Intensive Care Unit, and Surgical wards of a teaching hospital in Northeast Brazil. [n=485]

Failures $\mathbf{n}$
Context and transcribed record (in italics) 
Occasion ("when?")

Audience ("who?")

Purpose ("why?")

Content ("what?")
The pharmacist recorded guidance on the use of tramadol when the patient was no longer using it. Tramadol was suspended on the 3rd day of hospitalization, however the pharmacist recorded the guidance only on the 4th day. "I warn that tramadol can intensify this condition of constipation"

The nurse reported that losartan was not administered because the patient stated that it was suspended by the doctor, although the medication was present in the prescription of the day. "The patient refused the medication losartan $50 \mathrm{mg}$ because he states that the doctor suspended it" (Note: this report has been classified as having audience and purpose failures) In the nurse's report, it was not possible to find clarity in the outcome of the non-administration of pregabalin, since the drug was no longer used several times during hospitalization due to lack. "Patient refused pregabalin, I mean, the companion refused"

1) The patient reports using nine drugs at home. On the first day of hospitalization, the doctor prescribes eight medications, even recording that the previous pharmacotherapy would be maintained. "I prescribe medicines I used at home" 2) The patient reports having allergy to metoclopramide, but the doctor prescribes this medication for use when necessary.

\section{Hosted file}

Tables_IJCP.pdf available at https://authorea.com/users/393800/articles/507360-writtencommunication-about-the-use-of-medications-in-medical-records-during-patientshospitalization-in-brazil 